UMTRI-82-36

\title{
IMPROVED DRIVING PERFORMANCE FOLLOWING PERCEPTUAL TRAINING OF PERSONS WITH BRAIN DAMAGE
}

Michael Sivak

Carole S. Hill

Donald L. Henson

Barclay P. Butler

Sharon M. Silber

Paul L. Olson

PREPARED FOR

THE UNIVERSITY OF MICHIGAN

REHABILITATION ENGINEERING CENTER

SEPTEMBER 1982 
Tochaical Repert Documentation Page

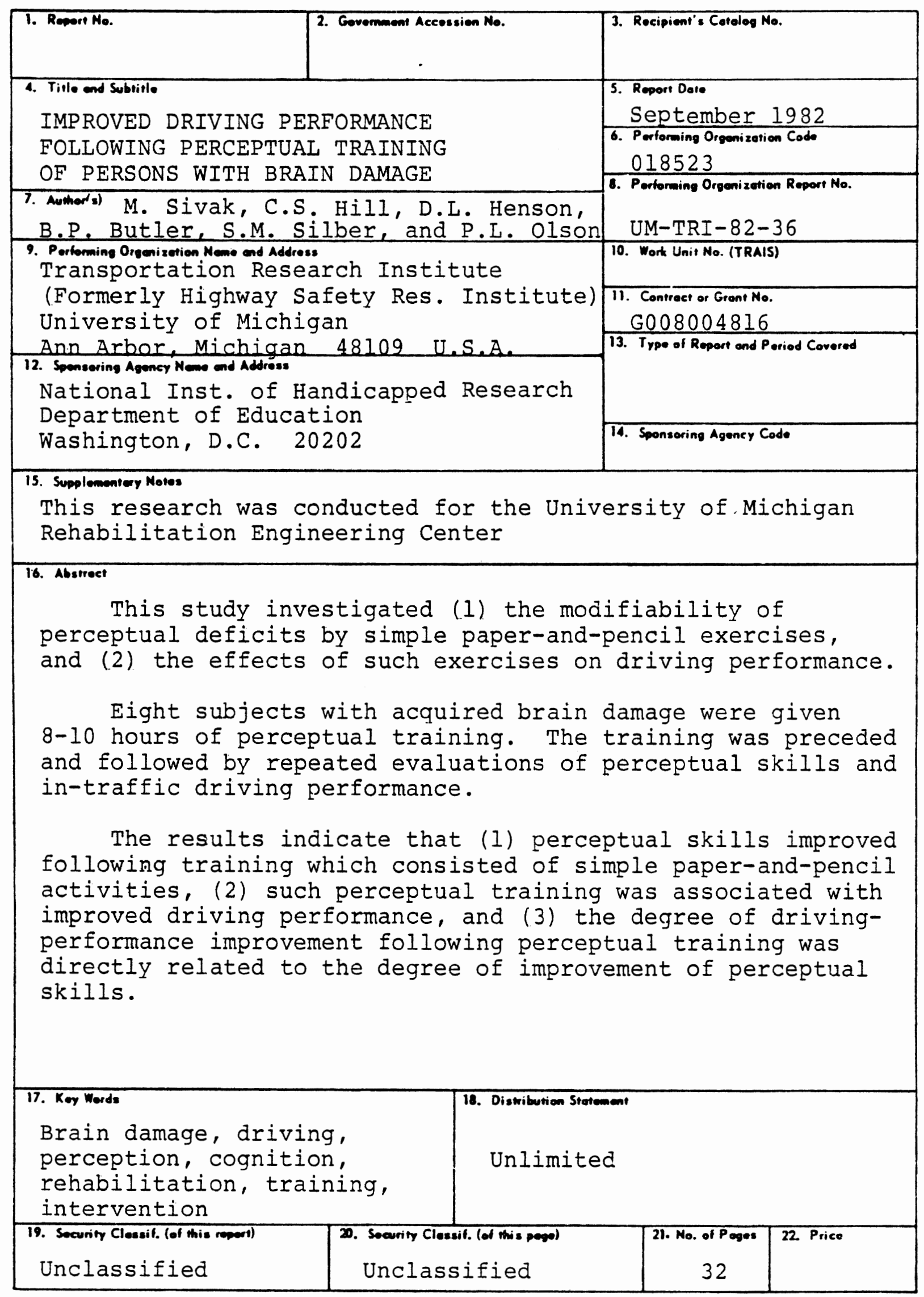




\section{ACKNOWLEDGMENTS}

This research was supported by the Rehabilitation Engineering Center of the University of Michigan through Grant G008005816 of the Office of Technology for the Handicapped, National Institute of Handicapped Research, Office of Special Education and Rehabilitation Services, Department of Education.

Appreciation is extended to Elizabeth Scheffler for help in administering the perceptual tests, Flora Simon for efficient secretarial assistance, and the subjects for participation in the study. 
TABLE OF CONTENTS

ACKNOWLEDGMENTS . . . . . . . . . . . . . . .

LIST OF TABLES . . . . . . . . . . . . . . . . . iv

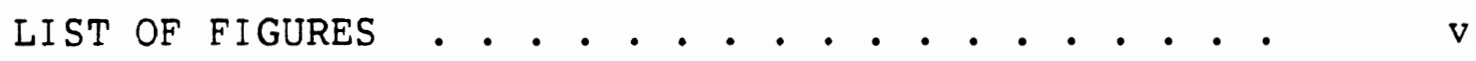

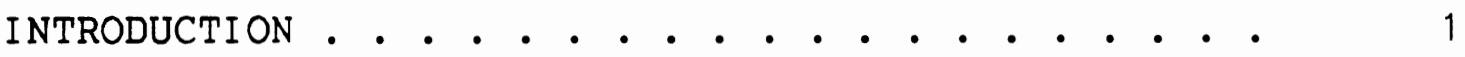

METHOD . . . . . . . . . . . . . . . . . 2

Overall Design of the Study . . . . . . . . . 2

Subjects •. . . . . . . . . . . . . . 3

Perceptual Evaluation . . . . . . . . . . . 44

Driving Evaluation . . . . . . . . . . . 8

Perceptual Training . . . . . . . . . . . . . 10

RESULTS •. • . . . . . . . . . . . . . . 19

Perceptual Changes . . . . . . . . . . . 19

Driving-Performance Changes . . . . . . . . 20

Relation of Driving Improvement to Perceptual

Improvement... . . . . . . . . . . 22

DISCUSSION . . . . . . . . . . . . . . . . 24

REFERENCES . . . . . . . . . . . . . . . 26 


\section{LIST OF TABLES}

1. Subject Characteristics . . . . . . . . 3

2. Computational Rules for Quantifying Change on Individual Perceptual Tests . . . . . . .

3. Perceptual Test Score Changes Following Training

4. All Pre- and Post-Training Driving Scores . .

5. The Last Two Pre-Training and the First PostTraining Driving Scores . . . . . . . . . 


\section{LIST OF FIGURES}

1. A schematic of the in-traffic driving course.

2. Pathfinding task. . . . . . . . . 13

3. Pattern visualization/identification task . . 15

4. Design construction and analysis task . . . . 17

5. Scatter plot of the driving improvement vs. perceptual improvement . . . . . . . . . . 
INTRODUCTION

Brain damage often results not only in physical impairment but in perceptual and cognitive deficits as well (e.g., Bardach, 1971). Sivak, Olson, Kewman, Won, and Henson (1981a) have shown that driving performance of persons with brain damage is directly related to the extent of their perceptual' impairment. Specifically, persons with brain damage who scored well on certain perceptual tests tended to show good driving performance as well. Furthermore, the results of analyses of covariance were consistent with the conjecture that the driving-related problems encountered by some of the persons with brain damage were due primarily to impaired perceptual skills. These findings suggest that therapeutic techniques capable of improving the impaired perceptual skills might improve driving performance as well. This hypothesis received tentative support from a pilot study (Sivak, Hill, Olson, and Henson, 1981b), and was more thoroughly tested in the present study.

"Perceptual" is used throughout this report as a shorthand for perceptual and cognitive. 
METHOD

Overall Design of the Study

The sequence of activities for the subjects was as follows:

(1) Pre-training evaluation of perceptual skills.

(2) Pre-training evaluation of in-traffic driving performance.

(3) Perceptual training.

(4) Post-training evaluation of perceptual skills.

(5) Post-training evaluation of in-traffic driving performance.

The pre-training perceptual evaluation was used also for selecting persons with perceptual deficits. Therefore, while 28 subjects were tested in this phase, only eight were given the training and the post-training evaluations.

The original design was to give each subject two pretraining driving tests (separated by at least two days). The assumption was that most of the spontaneous pre-training improvement (due to getting used to the car, the route, and the experimenters) would occur between the first and second tests. However, following testing of the first two subjects, a revised procedure was instituted. Specifically, if substantial improvement was observed between the first and second tests, additional tests were given until the performance appeared to have stabilized. ${ }^{2}$

\footnotetext{
${ }^{2}$ It proved to be the case that a third pre-training test was only given to one subject (see Table 4 ).
} 
Subjects

The criteria for selection of subjects were: (1) a history of acquired (as opposed to congenital) brain damage, (2) substantial perceptual deficits, (3) pre-injury driving experience, and (4) marked difficulty in relearning to drive.

Potential subjects were referred by professionals from a variety of rehabilitation settings. As noted earlier, eight subjects were included in the study; the others (of 28 persons screened) were not selected for a variety of reasons (primarily lack of evidence of perceptual impairment or presence of overriding visual problems). Personal history data are summarized in Table 1 for all eight subjects.

TABLE 1

SUBJECT CHARACTERISTICS

\begin{tabular}{c|c|c|c|l|c|c}
\hline \hline S & AGE & SEX & $\begin{array}{c}\text { YEARS } \\
\text { EDUC }\end{array}$ & \multicolumn{1}{|c|}{ ETIOLOGY } & $\begin{array}{c}\text { MONTHS } \\
\text { POST-ONSET }\end{array}$ & $\begin{array}{c}\text { YEARS DRIVING } \\
\text { EXPERI ENCE }\end{array}$ \\
\hline 1 & 19 & $\mathrm{~F}$ & 12 & Closed head injury & 11 & 1 \\
2 & 52 & $\mathrm{M}$ & $14+$ & Left CVA & 39 & 34 \\
3 & 62 & $\mathrm{M}$ & 16 & Right CVA & 8 & 50 \\
4 & 35 & $\mathrm{M}$ & 12 & Gunshot wound & 33 & 15 \\
5 & 48 & $\mathrm{M}$ & 14 & Right CVA & 11 & 32 \\
6 & 56 & $\mathrm{M}$ & 16 & Right CVA & 5 & 35 \\
7 & 23 & $\mathrm{M}$ & 12 & Closed head injury & 44 & 3 \\
8 & 42 & $\mathrm{~F}$ & 12 & Right CVA & 85 & 19 \\
\hline
\end{tabular}

NOTE: $\quad$ CVA = Cerebrovascular Accident 
Perceptual Evaluation

The psychological testing was conducted individually in a small, quiet office. The following psychological tests were used:

Picture Completion (Wechsler Adult Intelligence Scale Revised [Wechsler, 1981] and Wechsler Intelligence Scale for Children - Revised [Wechsler, 1974]). The subject's task is to identify the most important missing element in each of a series of sketched figures. An abridged version of the Wechsler Adult Intelligence Scale Picture Completion (Wechsler, 1955) had been found to be a good predictor of driving performance among persons with brain damage, and to be sensitive to brain damage (Sivak et al., 1981a). The standard procedure was used for both tests. In the analyses the data from both tests were pooled.

Picture Arrangement (Wechsler Adult Intelligence ScaleRevised [Wechsler, 1981]). This test involves 10 sets of pictures that subjects arrange in proper sequence so that each series will tell a story. According to Zimmerman and Woo-Sam (1973), Picture Arrangement measures factors such as "visual perception, synthesis into wholes through planning, and ability to see cause-effect relationships" (p. 154). Picture Arrangement had been shown to correlate significantly with driving performance among persons with brain damage, and to be sensitive to brain damage (Sivak et al., 1981a). The standard procedure was used. 
Block Design (Wechsler Adult Intelligence Scale Revised [Wechsler, 1981]). In this construction test, the subject is given red and white blocks, four for easier items and nine for more difficult items. The task is to construct copies of designs presented on a paper in smaller scale. Block Design is thought to measure visuospatial organization, and is especially sensitive to right hemisphere brain damage (Lezak, 1976). The standard procedure was used.

Symbol Digit Modalities Test (Smith, 1973). The task in this test is to substitute a number for each geometric figure arranged in a randomized series, according to a key that pairs different figures with numbers from one to nine. Since the language symbols (digits) are presumably processed primarily by the left hemisphere, and language-free symbols (figures) primarily by the right hemisphere, the substitution of numbers for geometric figures tests "the efficiency of many different central mechanisms in the two hemispheres" (Smith, 1973, p. 1). This test has been shown to be sensitive to brain damage (e.g., Smith, 1968; Sivak et al., 1981a). The standard procedure was used for both written and oral response administrations of the test. In the analyses the data from both the written and oral parts were pooled.

Trail Making Test (Reitan, 1966). In form $A$, the numbers 1 through 25 appear in randomly distributed circles on the page. The subject's task is to draw connecting lines 
between the circles in numerical order (as in a "dot-to-dot" puzzle). In form $B$, the encircled numbers 1 through 13 and encircled letters A through $L$ are randomly arranged on the page. The subject is asked to connect the circles, alternating between numbers and letters as follows: 1, A, 2, B, 3, C, etc. This test, which taps visual scanning and short-term memory, is sensitive to brain damage (Walsh, 1978). Times to complete parts A and B were recorded in seconds.

Cancellation Task. An array of typed capital letters (10 lines of 52 letters each) was presented to the subject. The subject was told to draw a line through each " $\mathrm{H}$," working quickly but trying to avoid mistakes. This task has been used by Diller et al. (1974) as a measure of visual scanning performance. The time to complete the task and number of errors were recorded.

The effect of perceptual training on scores from each test were quantified according to the computational rules listed in Table 2. The guiding principle for construction of each of these rules was to obtain indexes which could vary from -1.0 to +1.0 , inclusively. This requirement necessitated the changes in the denominator between improvement and decrement computations. The derived rules fall into three categories:

(1) For tests with an obtainable maximum number of correct responses (Picture Completion, Picture Arrangement, and Block Design), the post-pre 
difference was compared to either the maximum possible improvement or the maximum possible decrement. (The rule for improvement is analogous to that used by others [e.g., Hovland, Lumsdaine, and Sheffield, 1949; Weinberg et al., 1977].)

TABLE 2

COMPUTATIONAL RULES FOR QUANTIFYING CHANGES ON INDIVIDUAL PERCEPTUAL TESTS

\begin{tabular}{c|c|c}
\hline TEST & IMPROVEMENT & DECREMENT \\
\hline Picture Completion & $\frac{\text { Post-Pre }}{\text { Max-Pre }}$ & $\frac{\text { Post-Pre }}{\text { Pre }}$ \\
Picture Arrangement & $\frac{\text { Post-Pre }}{\text { Max-Pre }}$ & $\frac{\text { Post-Pre }}{\text { Pre }}$ \\
Symbol Digit & $\frac{\text { Post-Pre }}{\text { Max-Pre }}$ & $\frac{\text { Post-Pre }}{\text { Pre }}$ \\
Trails A & $\frac{\text { Post-Pre }}{\text { Post }}$ & $\frac{\text { Post-Pre }}{\text { Pre }}$ \\
Trails B & $\frac{\text { Pre-Post }}{\text { Pre }}$ & $\frac{\text { Pre-Post }}{\text { Post }}$ \\
Cancellation, Time & $\frac{\text { Pre-Post }}{\text { Pre }}$ & $\frac{\text { Pre-Post }}{\text { Post }}$ \\
Cancellation, Errors & $\frac{\text { Pre-Post }}{\text { Pre }}$ & $\frac{\text { Pre-Post }}{\text { Post }}$ \\
\hline
\end{tabular}

NOTE: $\quad$ Pre $=$ Pre-Training Score, Post = Post-Training Score, $\operatorname{Max}=$ Maximum Possible Score) 
(2) For the test without an obtainable maximum possible number of correct responses (Symbol Digit Modalities Test $^{3}$ ), the post-pre difference was compared to either the post score (in case of an improvement) or the pre score (in case of a decrement).

(3) For timed tests (Trail Making, Cancellation-Time) and for the error test (Cancellation-Errors), the pre-post difference was compared to either the pre score (in case of an improvement) or the post score (in case of a decrement).

\section{Driving Evaluation}

Driving performance was evaluated on a specially designed and validated in-traffic driving course (Sivak et al., 1981a), which was modeled after the work of Jones (1978). Each subject's in-traffic driving was tested on the same $10.4 \mathrm{mile}$ course in the northeast section of Ann Arbor. The traffic on the route during the testing was light-tomoderate with light pedestrian traffic. Approximately half of the route has a speed limit of $25 \mathrm{mph}$; additional sections have a limit of 30,35 , and $40 \mathrm{mph}$. Approximately two-thirds of the route is a two-lane road (with sections of one-way only); additional sections are four-lanes wide (both

${ }^{3}$ Symbol Digit Modalities Test has a theoretical maximum possible score. However, even for persons without brain damage, the 100th percentile score is less than $85 \%$ of the theoretical maximum (Centofanti, 1975). Consequently, this test can be conceptualized as not having an achievable maximum possible score. 
divided and undivided) and five-lanes wide (with a center turn lane). All driving was done during the daytime.

Each subject drove a car equipped with a dual-brake system, hand controls for accelerator and brakes, and (if desired) a steering knob. A driver educator (in the front seat) and a performance evaluator (in the rear seat) accompanied each subject. The performance evaluator was charged with rating the performance of each subject on predetermined actions along the route. The rating was done using a 2-point scale: well executed and not well executed. The evaluated actions belonged to one of the following five categories:

Gap Acceptance. Did the driver, in merging into traffic, accept a gap of a safe size, as opposed to accepting a gap too short or rejecting a gap long enough?

Limit Line. Did the driver position himself (herself) correctly at a stop sign, yield sign, or traffic signal?

Observation. Did the driver make the necessary observations (directly or via a mirror) at a stop or yield sign, prior to a requested change of lanes, and on turns? (Observations on turns and on straight portions were tabulated separately.)

Path. Did the driver stay within his/her lane without unsafe deviations from the intended direction? (Paths on turns and straight portions were tabulated separately.) 
Speed. Did the driver stay within $\pm 5 \mathrm{mph}$ of the speed limit? Did the driver maintain a smooth speed profile in turns and during acceleration? (Speeds on turns and straight portions were tabulated separately.)

Figure 1 illustrates the route with all of the 166 test actions and their locations on the route. In addition to the predetermined test actions, the evaluator noted all instances of incorrectly executed test actions that belonged to the five test categories. Due to these added test actions and the variability in traffic conditions, the actual number of the evaluated actions varied from subject to subject: the mean was 153.8 with a standard deviation of 8.1 .

As a global index of the driving performance, a Composite Driving Index (CDI) was computed, which was the mean of the proportions correct of each of the eight categories of driving actions. Thus, an obtained CDI could be between 0 and 1.00 .

\section{Perceptual Training}

Subjects received a total of 8 to 10 hours of individualized training, distributed over 5 to 9 sessions. The training was designed to require use of a wide range of perceptual skills and abilities. These included visual scanning, directed eye movements, spatial perception and discrimination, figure/ground differentiation, visual imagery, attentional capacity, and general problem-approach. 


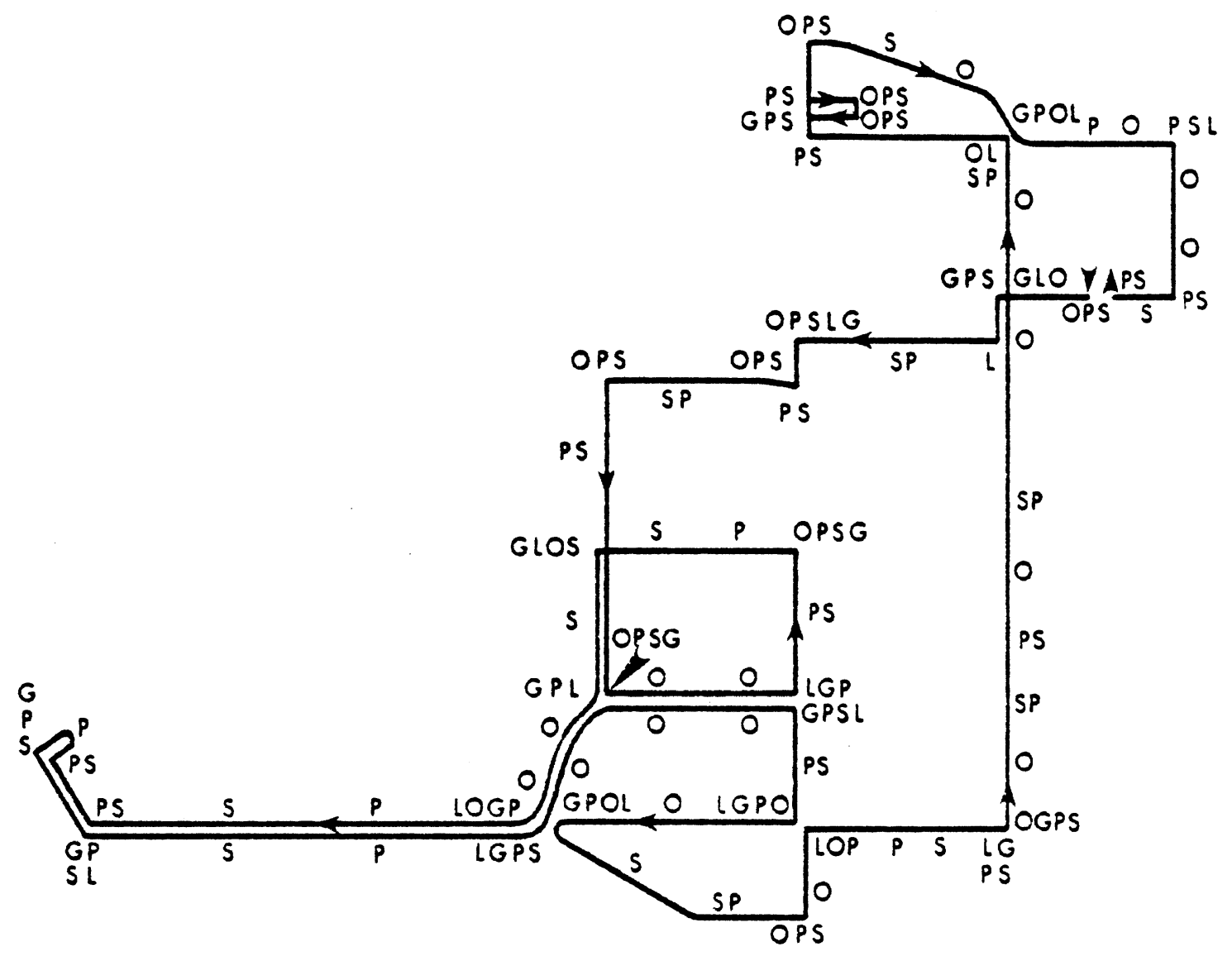

Figure 1. A schematic of the in-traffic driving course with the evaluated actions and their locations (G - Gap Acceptance, I - Limit Line, O - Observation, P - Path, S - Speed; for explanation see the text). 
There was a substantial degree of overlap from task to task as far as the underlying perceptual skills being utilized. The training was modified in response to the performance of each subject, both by varying the nature of the tasks as well as by varying the proportion of time spent on the various tasks. The specific tasks used in training were as follows:

Cancellation Tasks. The following parameters were varied: (1) size of the stimuli, (2) stimulus type (letters, arrows, percent signs, geometric shapes, brackets), target/nontarget ratio, (4) direction of scanning requested (left to right, right to left), and (5) difficulty of discriminating targets from non-targets. The subject was given feedback regarding the progress on a given task. (The particular cancellation task used in the pre- and posttraining tests was not included in the training material.)

Pathfinding Tasks. The subject was shown either a small (8.5" x 11" sheet) or a large (2' $\times 3^{\prime}$ poster), each containing randomly arranged circled letters with associated arrows to direct the gaze from one circle to the next (see Figure 2). The subject was given a starting point and asked to read the letters within the circles, following the order given by the arrows. The experimenter could increase the task difficulty by moving the display side-to-side or upand-down while the subject read from it.

Pattern visualization/identification. The subject viewed a regular matrix of circles containing letters and/or 


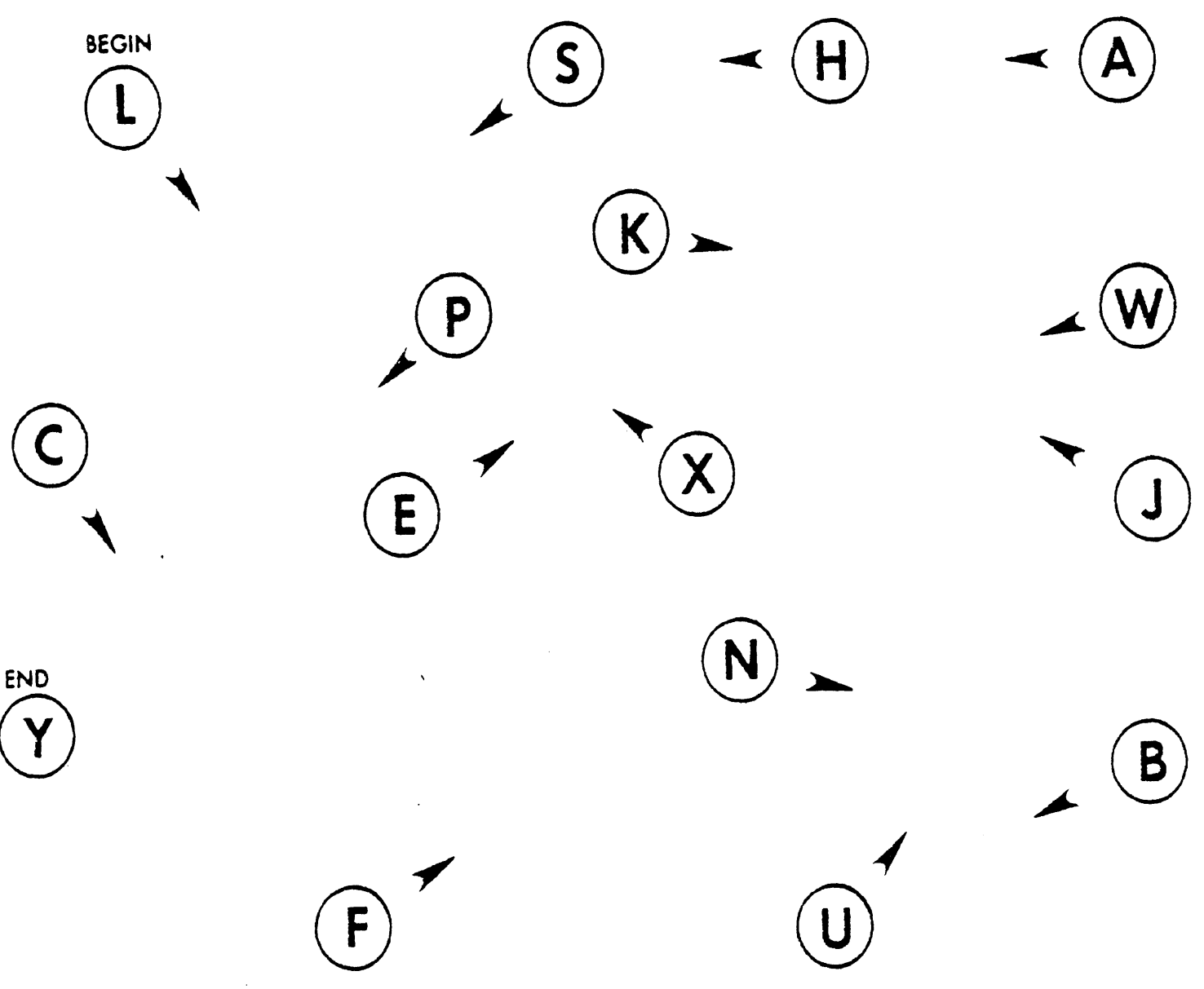

Figure 2. Pathfinding task. 
numbers (see Figure 3 ). The subject listened to a short sequence $(3-6)$ of the letters and/or numbers read aloud by the experimenter and was asked to visualize the pattern which would be formed if a line were drawn connecting the corresponding circles in the sequence read. This target pattern was either a simple geometric shape (e.g., diamond, square, or rectangle) or a letter of the alphabet. If the subject had difficulty with correctly identifying the pattern, the task was made easier by allowing $\mathrm{him} / \mathrm{her}$ to trace connecting lines with a finger.

Visual line-tracing. This task was based on Talland's Iine Tracing (1965), which is considered a test of visual tracking (Lezak, 1976). The subject viewed a pattern of intertwined lines, and was asked, starting with the line labeled "1" on the left margin, to indicate where each line ends on the right. The task was then repeated with direction of scanning reversed, i.e., from right to left. Both straight and curved line patterns were used. As with the preceding tasks, if the subject had difficulty, the use of a finger to trace the lines was allowed.

Pattern Matching ("Scan" game). This task was based on "Scan," a commercially produced game (copyright 1970 by Parker Brothers). There are two sets of 23 cards in this game. On each card are four unique designs as follows:

(1) "Shape" - A polygon of irregular outline.

(2) "Color" - Two concentric circles and a diamond on a square background; these four shapes are of four 
(B)

(H)

(P)

(

(E)

(G)

R

(

W

(K)

(F)

(b)

(x)

(A)

(c)

(D)

(1)

(M)

(s)

(4)

Figure 3. Pattern visualization/identification task. 
different colors, and the assignment of colors to shape varies from card to card.

(3) "Position" - a 4 x 4 grid with four black circles inside.

(4) "Pattern" - a pattern of Xs and Os arranged in five rows, with eight characters per row.

One set of cards was laid out in rows on the table in front of the subject. He or she was then given a card from the second deck and was to find the match for the specified design, while disregarding the remaining three designs on the card.

Design Construction and Analysis. The subject viewed a black and white geometric design similar but not identical to those of the Block Design test (Wechsler, 1981). The task was to construct a matching design using an assortment of black, white, and black/white cardboard squares (see Figure 4). (Similar training task was used by Diller et al., 1974.)

The following variations of the task difficulty were used to accommodate the subject's level of proficiency.

(1) Two sets of designs were available, the smaller (4square) designs being, in general, easier than the larger (9-square) designs. Some relatively proficient subjects practiced design construction using almost exclusively the 9-square designs; subjects who had a great deal of difficulty were given the 4-square designs. 

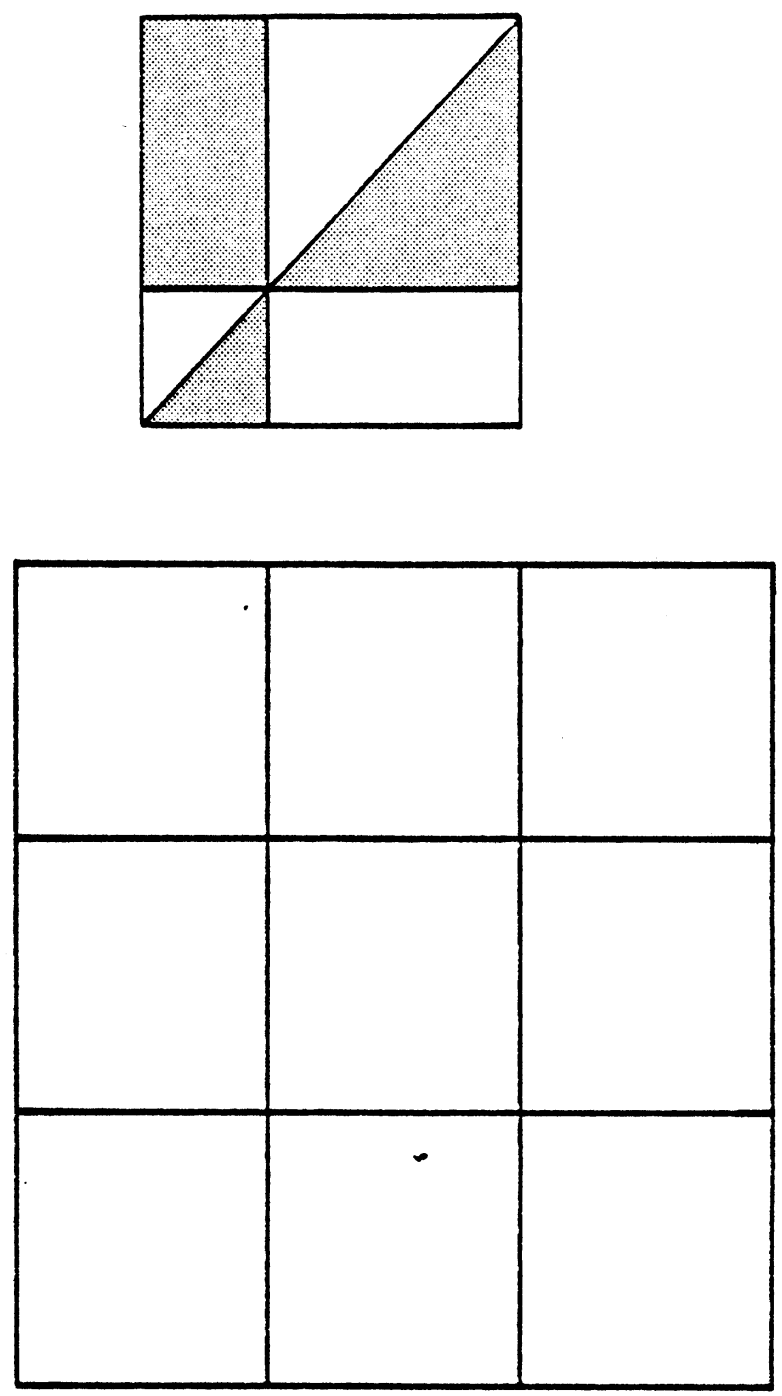

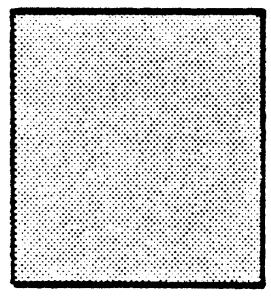

A

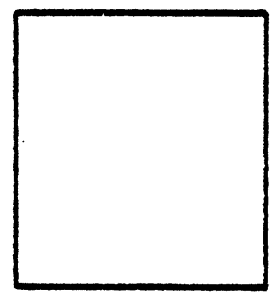

B

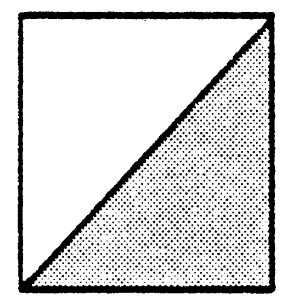

C

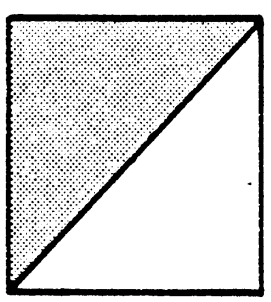

D

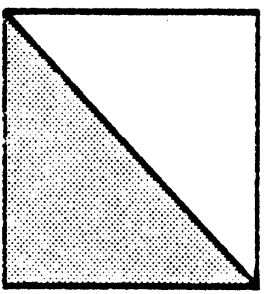

$\mathbf{E}$

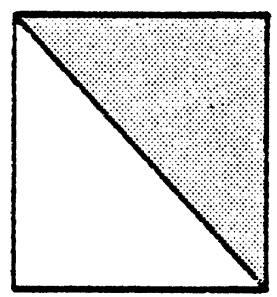

$\mathbf{F}$

Figure 4. Design construction and analysis task. 
(2) Two types of cueing were used as needed: (a) a response grid on which the cardboard squares could be placed (shown in center of Figure 4), or (b) a transparent overlay to be placed over the design being copied, which delineated the component squares of the design.

(3) Where appropriate, the experimenter offered verbal instructions regarding the general strategy of performing this task.

(4) A multiple-choice version of the designs was used to aid subjects in part-by-part analysis and comprehension of the patterns. As depicted in Figure 4, the subject viewed a design, a response grid, and the six possible candidates $(A-F)$ for each square of the grid needed to match the design. The subject was asked to point to or name which of the squares $A-F$ was needed for each square of the grid; if incorrect, a second guess was allowed. If the subject still failed to give the correct response, the transparent overlay was then put over the design. (This level of cueing always resulted in a correct response.) 
RESULTS

Perceptual Changes

The computed improvement (or decrement) scores for each test and each subject (according to the computational rules in Table 2) are presented in Table 3. A global index of perceptual change, a Delta Composite Perceptual Index ( $\triangle \mathrm{CPI}$ ), was computed for each subject by averaging the eight individual test-change scores. (Thus an obtained $\triangle C P I$ could vary between -1.0 and +1.0 ). The $\triangle$ CPIs are also listed in Table 3 .

TABLE 3

PERCEPTUAL TEST SCORE CHANGES FOLLOWING TRAINING

\begin{tabular}{l|r|r|r|r|r|r|r|r}
\hline \multirow{2}{*}{ TEST } & \multicolumn{7}{|c}{ SUBJECT } \\
\cline { 2 - 7 } & 1 & 2 & 3 & 4 & 5 & 6 & 7 & \multicolumn{1}{c}{8} \\
\hline \multirow{2}{*}{ Picture Completion } & .59 & -.06 & .42 & .32 & .04 & .47 & .11 & .17 \\
Picture Arrangement & -.25 & -.53 & .00 & .22 & .00 & .14 & -.50 & .00 \\
Block Design & .14 & .15 & .25 & .30 & .15 & .35 & .16 & .29 \\
Symbol Digit & .24 & .15 & .21 & .65 & -.07 & .03 & .08 & .22 \\
Trails A & .17 & .35 & .36 & .75 & -.07 & .19 & .19 & .08 \\
Trails B & .31 & -- & .46 & -- & -- & .29 & .29 & .13 \\
Cancellation, Time & .21 & -- & .38 & .40 & .05 & -.31 & .00 & .43 \\
Cancellation, Errors & .93 & -- & .83 & .95 & .88 & 1.00 & .12 & .00 \\
\hline
\end{tabular}

NOTE: "--" indicates that the test was either not administered, inadvertently not timed, or not completed by the subject. 
Driving-Performance Changes

Table 4 presents the pre- and post-training driving (CDI) scores for each subject.

TABLE 4

ALL PRE- AND POST-TRAINING DRIVING (CDI) SCORES

\begin{tabular}{c|c|c}
\hline SUBJECT & CDI ${ }_{\text {Pre }}$ & ${ }^{C D I_{\text {Post }}}$ \\
\hline 1 & $.73, .85$ & $.91, .91$ \\
2 & $.80, .86$ & $.86, .88$ \\
3 & $.67, .77, .72$ & .82 \\
4 & $.75, .72$ & $.83, .83$ \\
5 & $.90, .84$ & .90 \\
6 & $.91, .89$ & .93 \\
7 & $.82, .80$ & .85 \\
8 & $.74, .80$ & .90 \\
\hline
\end{tabular}

To estimate the effect of perceptual training on driving performance, two planned comparisons were performed using the method for repeated measures (winer, 1971). The first planned comparison evaluated the test/retest spontaneous change in the CDIs immediately prior to the start of the training, by contrasting the last two pretraining CDI scores (see Table 5). The hypothesis that this change would not be significantly different from zero was supported by the result of the planned comparison $(\underline{F}<1)$. 
THE LAST TWO PRE-TRAINING AND THE FIRST POST-TRAINING DRIVING SCORES, AND THE ASSOCIATED TRAINING EFFECT ( $\triangle C D I)$

\begin{tabular}{c|c|c|c|c}
\hline $\mathrm{S}$ & $\mathrm{CDI}_{\text {Last-1 Pre }}$ & $\mathrm{CDI}_{\text {Last }}$ Pre & $\mathrm{CDI}_{\text {First Post }}$ & $\Delta$ CDI \\
\hline 1 & .73 & .85 & .91 & .06 \\
2 & .80 & .86 & .86 & .00 \\
3 & .77 & .72 & .82 & .10 \\
4 & .75 & .72 & .83 & .11 \\
5 & .90 & .84 & .90 & .06 \\
6 & .91 & .89 & .93 & .04 \\
7 & .82 & .80 & .85 & .05 \\
8 & .74 & .80 & .90 & .10 \\
\hline$\overline{\mathrm{x}}$ & .80 & .81 & .88 & .07 \\
\hline
\end{tabular}

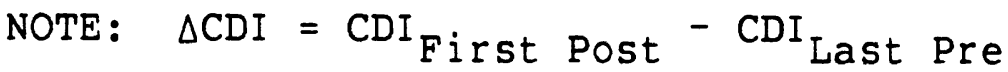

The second planned comparison evaluated the effect of training by comparing the first post-training CDI scores against the last pre-training CDI scores (see Table 5). The hypothesis that there would be a significant increase from the pre- to post-training scores was supported by the result of the planned comparison $(\underline{F}=10.39$, df $=1,14, \underline{p}<.01)$.

The above two comparisons are not independent. Therefore, the Bonferonni correction (Morrison, 1976) was also used to arrive at more conservative estimates of statistical significance. However, this correction did not change the findings: the first comparison remained 
statistically not significant $(\underline{F}<1)$, the second remained statistically significant $(\underline{F}=10.39, \underline{p}<.05)$.

Relation of Driving Improvement to Perceptual Improvement

Figure 5 presents a scatter plot of the drivingperformance changes ( $\triangle C D I s$ from Table 5 ) versus the corresponding perceptual changes ( $\triangle \mathrm{CPI}$ s from Table 3 ) for each of the eight subjects. The dashed line in Figure 5 is the best-fitting regression line. The product-moment correlation between the two variables is $\underline{r}=.73, \underline{p}<.025$ (one-tail test); $\mathrm{p}<.05$ (two-tail test). Therefore, $53 \%$ of the variance of the driving-performance improvement is accounted for by the perceptual improvement $\left(\underline{r}^{2}=.53\right)$. 


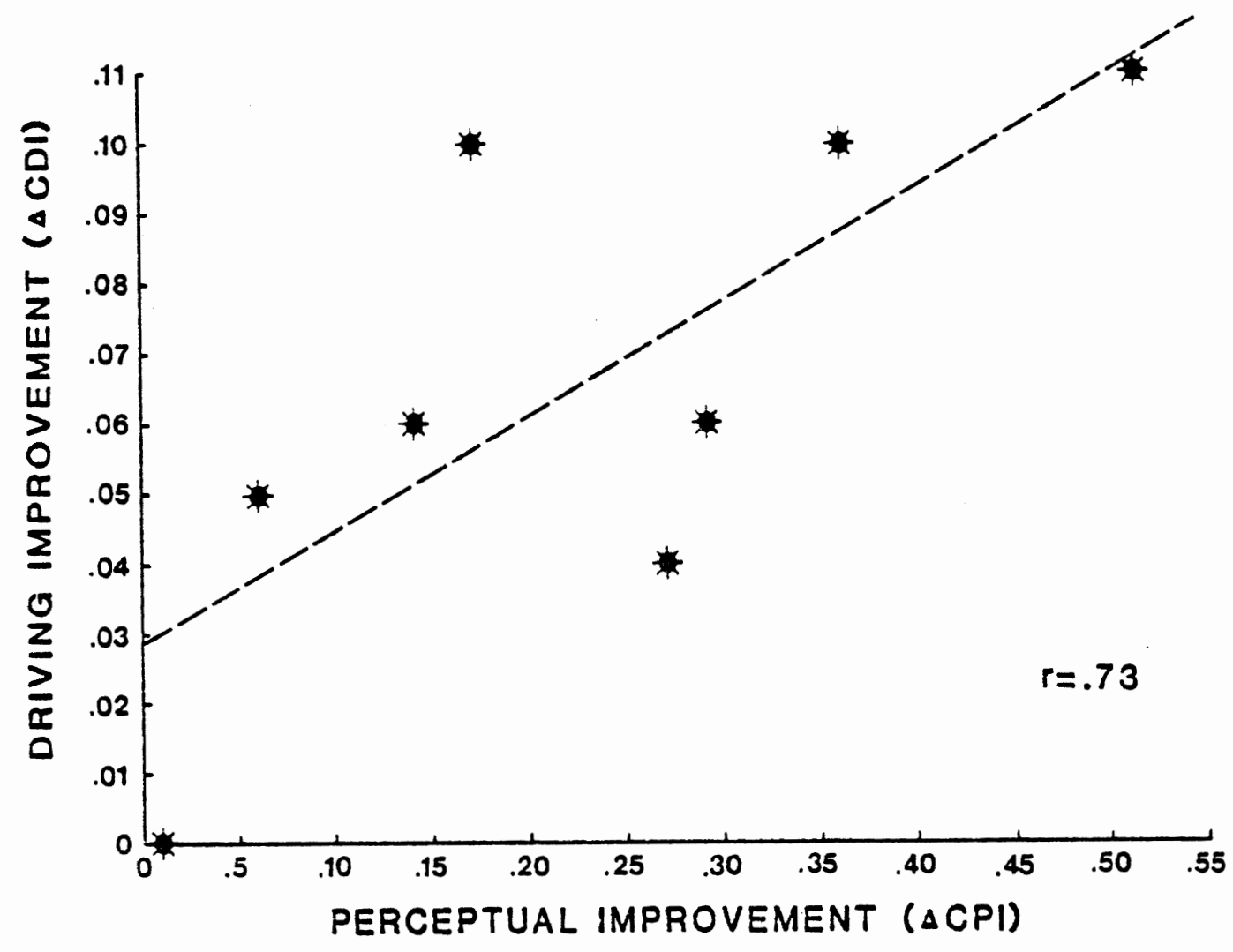

Figure 5. Scatter plot of the driving improvement vs. perceptual improvement. (The dashed line is the best-fitting regression line.) 


\section{DISCUSSION}

The present findings, in conjunction with the findings of Sivak et al. (1981a), indicate the following:

(1) Driving performance of persons with brain damage is affected by their residual perceptual capabilities.

(2) Perceptual skills are amenable to training which consists of simple paper-and-pencil activities.

(3) Such perceptual training results in improved driving performance.

(4) The degree of driving-performance improvement following perceptual training is directly related to the degree of improvement of perceptual skills.

The utilized design attempted to begin the perceptual training when the driving performance had stabilized. The finding that the final pre-training test/retest changes in the driving-performance scores were not significantly different from zero, indicates that this indeed was achieved. Consequently, the significant improvement in the driving performance following the training implies that this improvement was a consequence of the training.

While the present findings are very promising, validations with larger samples are necessary to firmly establish the benefits of perceptual training. Furthermore, several important issues have not been addressed yet and will have to be eventually researched. These issues include the following: What is the role of the etiology of the 
brain damage in determining the success of perceptual training? What are the optimal time course, format, and content of perceptual training, and how might these parameters vary with etiology? What are the long-term benefits of perceptual training?

Finally, the present findings provide a strong argument for dealing with the underlying causes of functional deficits and not merely with the symptoms. The argument is not that direct driving instructions do not provide positive results; they may (Sivak et al., 1981b). Nevertheless, if driving is improved following perceptual training, it is likely that a range of other activities of daily living (where perceptual skills are often essential) would benefit as well. Therefore, perceptual training to improve driving performance might indeed constitute perceptual training to improve driving, walking, general navigation, as well as home and work activities. The potentially broad implications of perceptual training remain to be ascertained. 
Bardach, J. L. Psychological factors in the handicapped driver. Archives of Physical Medicine and Rehabilitation, 1971, 52, 328-332.

Centofanti, C.C. Selected somatosensory and cognitive test performance as a function of age and education in normal and neurologically abnormal adults. Unpublished doctoral dissertation, University of Michigan, Ann Arbor, 1975.

Diller, L., Ben-Yishay, Y., Gerstman, L. J., Goodkin, R., Gordon, W. , Weinberg, J., Mandelberg, I., Schulman, P., and Shah, N. Studies in cognition and rehabilitation in hemiplegia. New York: New York University Medical Center, Institute of Rehabilitation Medicine, Rehabilitation Monograph No. 50, 1974.

Hovland, C. I., Lumsdaine, A. A., and Sheffield, F. D. Mass communication. Princeton, NJ: Princeton University Press, 1949.

Jones, M. H. Driver performance measures for safe performance curriculum. Los Angeles: University of Southern California, Technical Report 78-3, March 1978.

Lezak, M. D. Neuropsychological assessment. New York: Oxford University Press, 1976.

Morrison, D.F. Multivariate statistical methods (2nd ed.). New York: McGraw-Hill, 1976.

Reitan, R. M. A research programme on the psychological effects of brain lesions in human beings. In, N. R. Ellis (Ed.), International Review of Research in Mental Retardation. New York: Academic Press, 1966.

Sivak, M., Olson, P. L., Kewman, D. G., Won, H., and Henson, D. H. Driving and perceptual/cognitive skills: behavioral consequences of brain damage. Archives of Physical Medicine and Rehabilitation, 1981, 므, 476-483. (a)

Sivak, M., Hill, C. S., Olson, P. L., and Henson, D. L. Preliminary testing of techniques to improve driving performance of persons with brain damage via perceptual/cognitive training. Ann Arbor, MI: Highway Safety Research Institute, University of Michigan, Interim Report No. UM-HSRI-81-12, March 1981. (b)

Smith, A. The Symbol-Digit Modalities Test: a neuropsychological test of learning and other cerebral disorders. In J. Hellmuth (Ed.), Learning disorders. 
Seattle, WA: Special Child Publications, 1968, pp. 83-91.

Smith, A. Symbol Digit Modalities Test. Los Angeles, CA: Western Psychological Services, 1973.

Talland, G. A. Deranged memory. New York: Academic Press, 1965.

Walsh, K. W. Neuropsychology. Edinburgh, Great Britain: Churchill Livingston, 1978.

Wechsler, D. Wechsler Adult Intelligence Scale. New York: Psychological Corporation, 1955.

Wechsler, D. Wechsler Intelligence Scale for Children Revised. New York: Psychological Corporation, 1974.

Wechsler, D. Wechsler Adult Intelligence Scale - Revised, New York: Psychological Corporation, 1981.

Weinberg, J., Diller, L., Gordon, W. A., Gerstman, L. J., Lieberman, A., Lakin, P., Hodges, G., and Ezrachi, 0 . Visual scanning training effect on reading-related tasks in acquired right brain damage. Archives of Physical Medicine and Rehabilitation, 1977, 58, 479-486.

Winer, B. J. Statistical principles in experimental design (2nd ed.). New York: McGraw-Hill, 1971.

Zimmerman, I. L. and Woo-Sam, J. M. Clinical interpretation of the Wechsler Adult Intelligence Scale. New York: Grune and Stratton, 1973. 